\title{
Effects of Responses to Depression on the Remediation of Depressive Affect
}

\author{
Jannay Morrow and Susan Nolen-Hoeksema \\ Stanford University
}

\begin{abstract}
The effects of different types of responses to a depressed mood on the duration and severity of the mood were examined. On the basis of Nolen-Hoeksema's (1987) response styles theory of depression, it was hypothesized that distracting, active responses would be more effective in alleviating a depressed mood than would ruminative, passive responses. A depressed mood was induced in 35 male and 34 female Ss, and subjects were randomly assigned to engage in 1 of 4 types of responses: an active task that distracted them from their mood; a passive, distracting task; an active task designed to lead to ruminations about their mood; or a passive, ruminative task. As predicted, the greatest remediation of depressed mood was found in Ss in the distracting-active response condition, followed in order by the distracting-passive, ruminative-active, and ruminative-passive response conditions. Degree of rumination had a greater impact on remediation of depressive affect than level of activity, with greater rumination leading to lesser remediation of depressive affect. In addition, the effects of the response tasks were limited to depressed mood. The implications of these results for interventions with depressed persons are discussed.
\end{abstract}

Most individuals become mildly to moderately depressed at least occasionally. Such episodes can be caused by a large variety of psychosocial and biological factors (Beckham \& Leber, 1985). For most people, the symptoms of depression never become very severe and pass in a few hours or days. For some individuals, however, these mild to moderate depressive episodes become progressively more severe and last several days, weeks, or months. What are the causes of the individual differences in the duration and severity of depressive episodes?

In the study described here, we tested the hypothesis that the ways individuals respond to their symptoms of depression influence the severity and duration of depressed mood. This hypothesis is based on Nolen-Hoeksema's (1987) response styles theory of depression. According to this theory, ruminative responses to a depressed mood lead to longer lasting and more severe episodes of depression, whereas distracting responses shorten depressive episodes. Below we describe this theory in more detail and review previous studies relevant to the theory.

\section{Ruminative and Distracting Responses to Depression}

The response styles theory of depression (Nolen-Hoeksema, 1987) proposes that individuals who engage in ruminative responses to depressed mood will experience amplification and prolongation of the mood, whereas individuals who engage in distracting responses to their depressed mood will experience relief from that mood. Ruminative responses are cognitions

We thank Miriam Harris and Karen Schlaepfer for their assistance in conducting this experiment. We also thank Barbara L. Fredrickson and Ghassan Ghandour for their comments on earlier drafts.

Correspondence concerning this article should be addressed to Jannay Morrow, Department of Psychology, Jordan Hall Building 420, Stanford University, Stanford, California 94305. and behaviors that repetitively focus the depressed individual's attention on his or her symptoms and the possible causes and consequences of those symptoms. Examples of ruminative responses to depression are isolating oneself to think about how one is feeling, writing in a diary about how one is feeling, or repeatedly telling others how badly one feels. Sometimes individuals may ruminate about recent bad events as possible causes of their depressive symptoms, but often ruminations focus on the symptoms of depression, including sadness, apathy, and fatigue. Individuals may focus on their depressive symptoms to try to assess and remedy this aversive state. According to the response styles theory, however, this rumination will often simply make the person more depressed. In contrast, distracting responses are cognitions and behaviors that take the individual's mind off his or her symptoms of depression. Examples include engaging in an activity with friends, or working on a hobby that requires concentration in order to distract oneself from one's mood.

There are at least three mechanisms by which rumination can amplify a depressed mood and distraction can relieve it. First, depressed mood appears to increase the likelihood that individuals will recall negative information and make negative inferences about events (Blaney, 1986; Bower, 1981; Teasdale, 1985). Compared with people in neutral or happy moods, people in sad moods (a) show selective recall of sad memories from their lives (Bower, 1981; Clark \& Teasdale, 1982; Teasdale \& Fogarty, 1979), (b) falsely remember receiving more negative evaluations from an experimenter (Natale \& Hantas, 1982), (c) interpret their own behavior in social interactions more negatively (Forgas, Bower, \& Krantz, 1984), (d) rate their life satisfaction as low (Schwarz \& Clore, 1988), (e) form more negative impressions of others (Forgas \& Bower, 1987), (f) make more negative interpretations of thematic apperception test (TAT) cards (Bower, 1981), and (g) are less likely to show an optimistic 
illusion of control over outcomes (Alloy, Abramson, \& Viscusi, 1981). Because of these effects of mood on thinking, individuals who ruminate about the causes and consequences of their depressed moods while they are depressed will be more likely to reach negative conclusions concerning these issues than persons who initially distract themselves from their mood and wait until the depressed mood has lifted before considering these issues.

Second, rumination can enhance the effects of existing maladaptive cognitive styles by bringing maladaptive cognitions to the individual's mind relatively more often, thereby amplifying depressed mood (Zullow, 1984; Zullow, Oettingen, Peterson, \& Seligman, 1988). Zullow (1984) found that college students who showed both a tendency to ruminate over negative events and a pessimistic style of explaining events were more prone to depression than were students who only showed ruminations or a tendency toward pessimistic explanations.

Finally, rumination interferes with attention, concentration, and the initiation of instrumental behaviors (Kuhl, 1981; Lewinsohn, Hoberman, Teri, \& Hautzinger, 1985). Studies of achievement-related behaviors have found that people who become anxious or pessimistic about their performance on exams tend to ruminate on self-related, task-irrelevant cognitions (e.g., Brockner \& Hulton, 1978; Heckhausen, 1980; Kuhl, 1981; Sarason, 1975). The impaired concentration and lowered expectancies for future success that result from this ruminative self-focus lead to debilitated performance. Self-focus also interferes with the performance of effective interpersonal behavior (Coyne, Metalsky, \& Lavelle, 1980; Fenigstein, 1979; Strack, Blaney, Ganellen, \& Coyne, 1985). Failures that can accumulate from the attentional and behavioral deficits produced by ruminative responses may lead to a greater sense of helplessness in controlling one's environment, thereby contributing to depression (cf. Seligman, 1975). On the other hand, engaging in activity to distract oneself when depressed increases one's chances for controlling the environment and obtaining positive reinforcement, thereby dampening an existing depressed mood. Although the study reported here is the first direct test of the response styles theory, the results of studies of self-focus and depression and of coping styles for distressing events are consistent with the theory.

\section{Self-Focus and Depression}

One aspect of ruminative responses to depression is self-focus. Many studies have reported a link between excessive selffocus and depression (for a review, see Pyszczynski \& Greenberg, 1987). For example, Scheier and Carver (1977) found that subjects experience significantly greater increases in induced depressed mood when in situations promoting self-awareness (i.e., when seated in front of a mirror). Moreover, depressed psychiatric patients report more negative affect when made selfaware by the presence of a mirror than depressed patients not made self-aware (Gibbons et al., 1985). Self-focus can heighten depressed mood by increasing the probability that an individual will make internal attributions for negative events (Fenigstein \& Levine, 1984), by increasing negative expectancies about the future (Carver, Blaney, \& Scheier, 1979; Pyszczynski, Holt, \& Greenberg, 1987), and by interfering with performance on tasks (Fenigstein, 1979). Because the response styles theory holds that rumination consists of focus on one's symptoms of depression and repetitive thoughts about the possible causes and consequences of these symptoms, the results of these studies on self-awareness and depression are in line with the hypothesis that people who engage in rumination when depressed will remain depressed longer than people who do not.

\section{Coping With Distressing Events}

Most studies of coping styles and depression have focused on how people cope with concrete events, such as job loss, and not how they cope with their symptoms of depression. Even so, the results of several of these studies indicate that engaging in ruminative sorts of thoughts and behaviors following a distressing event is associated with elevated levels of depression. For example, among individuals coping with a serious physical illness, those who engage in "wishful thinking" (e.g., wishing they could change the way they feel) show more symptoms of psychological distress than those who do not use this type of coping (Felton \& Revenson, 1984). Furthermore, depressed adults are more likely to use wishful thinking as a coping strategy than are nondepressed adults (Coyne, Aldwin, \& Lazarus, 1981). Depressed individuals are also more likely than nondepressed individuals to seek emotional support from others and to desire much more information about a problem situation. Coyne et al. (1981) characterized this information seeking as rumination (p. 445). Finally, depressed persons are less likely than nondepressed persons to say they would use distracting behaviors or spend time with friends in response to a distressing event and are more likely to become passive (Parker \& Brown, 1982).

In sum, these studies of self-focus and coping styles support the hypothesis that people who are made self-aware when depressed or who use ruminative, passive coping styles in response to distressing events are at increased risk for prolonged depressive symptoms.

\section{Effects of Activity Level on Depression}

According to the response styles theory, the activity level of individuals' responses to depression will affect the duration of their depression. Outcome studies of cognitive-behavioral treatments of depression indicate that increased pleasant activities and increased activity level, in general, are associated with the remediation of the affective symptoms of depression (Batson, Coke, Chard, Smith, \& Taliaferro, 1979; Fuchs \& Rehm, 1977; Lewinsohn \& Libet, 1972; Rehm, 1982). This improvement is attributed to increased positive outcomes and the resultant increase in external and internal reinforcement that occurs from engaging in these activities (Heiby, 1983a, 1983b; Lewinsohn, 1986; Rehm, 1986). Passive responses generally do not lead to increased positive outcomes because the individual is not engaging in behaviors or interacting with others. As such, passive responses generally do not increase opportunities for external or internal positive reinforcement and are not expected to increase positive affect. In fact, passive responses may perpetuate or worsen a depressive episode by limiting the opportunities for success and reinforcement.

Research on the psychological effects of acute and long-term physical activity also indicates that increased activity level can 
improve mood. Brief, mild activity, such as walking on a treadmill for 20 min, improves mood (Bahrke \& Morgan, 1978). Low levels of long-term activity, such as bowling, are also associated with lower levels of psychological distress (Byrd, 1964). Moreover, programs involving vigorous, long-term activity, such as aerobics or jogging, can be effective treatments for moderate clinical depression (Doyne, Chambless, \& Beutler, 1983; Greist et al., 1979; McCann \& Holmes, 1984). Many theorists attribute the mood effects of acute and moderate physical activity to the psychological, distracting effects of exercise and not to the physiological effects of the exercise (Morgan, 1985). Passive responses to depressed mood do not distract an individual's attention from distressing stimuli, and may actually facilitate focusing on these stimuli. Consequently, passive responses are not expected to relieve depressed mood. Thus, active responses should lead to greater relief from depression because they increase the individual's chances of receiving reinforcement and because they help distract the individual. Pilot work by Needles (1987) on the relationship between levels of depression and selfreported responses to depression, however, indicates that the extent to which subjects' responses were active versus passive was not as good a predictor of levels of depression over a 3-month period as was the extent to which their responses were ruminative versus distracting. One reason for this result seemed to be that some subjects engaged in rumination even while active (e.g., thought about their problems while they were jogging). Therefore, degree of rumination, relative to activity level, should exert a stronger influence on the duration of depressed mood, even though active responses should lead to greater remediation of depression than passive responses.

In this study we predicted that distracting responses would be more effective in reducing depressive affect than ruminative responses and that active responses would be more effective in remediating depressive affect than passive responses. We also expected that degree of rumination would have a greater impact on depressed affect than level of activity. Finally, we predicted that the effects of degree of rumination and level of activity on the remediation of depressive affect would be additive, not interactive. Either distraction or activity should help an individual to recover from a depressed mood. Yet, responses that are both distracting and active should be the most effective in lifting the mood, and responses that are both ruminative and passive should be least effective in lifting the mood. To test these predictions, depressed mood was first induced by having subjects read a depressing story while sad music played in the background. Subjects were then randomly assigned to one of four response task conditions. The response tasks were distinguished by two factors: degree of rumination (ruminative vs. distracting) and activity level (passive vs. active). Ruminative tasks required subjects to be self-focused and to concentrate on their emotions. Distracting tasks diverted subjects' attention away from how they were feeling by requiring them to focus their attention on external, non-emotion-related events. In addition, the tasks required either mild physical activity (active tasks) or almost no physical activity (passive tasks). Crossing degree of rumination with activity level produced four distinct response task conditions: (a) distracting-active, (b) distracting-passive, (c) ruminative-active, and (d) ruminative-passive. To test whether the effects of response styles were specific to depressive affect, changes in sadness, hostility, and anxiety in the four conditions were assessed.

\section{Method}

\section{Subjects}

Thirty-five male and 34 female undergraduates enrolled in introductory psychology at Stanford University received course credit for their participation in this study.

\section{Materials}

Written materials. Subjects were asked to complete three packets of questionnaires during the experiment. Each packet contained a questionnaire that asked subjects to rate their present levels of sadness, hostility, and anxiety on 9-point Likert scales. Mood questionnaires were administered prior to mood induction (preinduction), immediately following mood induction (postinduction), and immediately following completion of the response task (postresponse). A number of filler questionnaires were included to bolster the cover story that the experimental hour was composed of a variety of independent studies (referred to as separate phases of the experimental session).'

Response tasks. Four experimental groups-distracting-active, distracting-passive, ruminative-active, and ruminative-passive-were distinguished by preassigned experimental tasks designed as analogues of responses to depressive episodes.

In both passive conditions, subjects sat and read sentences that were printed individually on note cards. Subjects were asked to read each sentence silently to themselves and to "think about and concentrate on the meaning" of the sentence. Different sets of cards distinguished the distracting-passive and the ruminative-passive groups. The distracting-passive group read sentences that focused on external events (e.g., "Canada's biggest industry is lumber"; "It would be interesting to visit other countries"; and "The NBA playoffs will be soon"). The content of the sentences presented to ruminative-passive subjects was self- and emotion-focused (e.g., "I often wonder why I feel the way I do"; "Some days I feel strange"; and "Sometimes I just sit and think"). Each set of cards contained 82 sentences.

Subjects in the active groups completed "giant" Q-sorts (adapted from Block, 1961). Subjects sorted 34 index cards into seven ranked groups. Because the Q-sort category headings were affixed to a table and spaced over a distance greater than $8 \mathrm{ft}$, subjects in the active conditions could complete the task only by standing and walking back and forth numerous times. Distracting-active subjects completed an externally focused Q-sort titled "Countries of the World." These subjects rank ordered 34 countries from most to least industrialized. The ruminativeactive group completed an emotions Q-sort. They were told to focus on how they felt at the moment and to group the cards accordingly. This Q-sort contained 15 negative items (e.g., "depressed"), 11 positive items (e.g., "cheerful"), and 8 neutral items (e.g., "preoccupied").

Affect induction. Two sadness induction techniques, proved reliable in previous experiments, were combined to induce sadness. Subjects read a depressing story (adapted from Keltner \& Ellsworth, 1987) while sad music played in the background (Clark, 1983; Sutherland, Newman, \& Rachman, 1982). Subjects were asked to read the story and imagine that the events depicted in the story were happening to them. The story vividly described the unexpected and painful death of the reader's mother. The use of sad background music to induce depressed affect was based on the musical mood induction procedure, or MIP (Clark, 1983; Sutherland et al., 1982), and has been successful when

\footnotetext{
${ }^{1}$ Debriefing revealed that the cover story was successful in preventing subjects from discovering the true intent of the experiment.
} 
accompanied by imagery techniques (Morrow, 1986). In the original version of the MIP, subjects listened to mood suggestive music, Barber's Adagio for Strings, and were asked to "try really hard to get into the mood, using whatever means they find most effective." The present study used the same music; yet, because the story was used to induce the initial depressed mood and the music was intended to accentuate these mood effects, subjects were not instructed to actively attend to the music. Rather, they were told that the music was intended to "help them imagine the events in the story." To avoid obvious demand characteristics, mood was never mentioned in the experimental instructions, and the story and music were introduced as imagery tasks that were part of a cognitive psychology experiment. While subjects read the story and worked on the questionnaires, the music played at an audible yet unobtrusive level.

Light signal. Subjects could trigger a light switch from inside the laboratory and signal the experimenter outside the room that they had completed a phase of the experiment. This light served three purposes: (a) It allowed subjects to remain seated during the experiment; (b) it provided subjects with privacy while reading the story and filling out the questionnaires; and (c) it helped to segment the experiment into separate phases, thus bolstering the cover story that the experiment was composed of several independent studies.

\section{Procedure}

Subjects were randomly assigned to one of the experimental groups and tested individually. Upon arrival at the experimental room, each subject was greeted by a female experimenter and asked to carefully read and then sign a consent agreement. Subjects were told that the experimenter would leave the room and at that time they should begin filling out the questionnaires for the first phase of the experiment. Subjects were told to signal the experimenter when they had finished the questionnaires for Phase 1. When the light went on, the experimenter immediately reentered the room and began Phase 2. She told subjects they would complete a second packet of questionnaires after they finished the "imagination task" that was mentioned in the consent form. Subjects then read the instruction sheet labeled "Processes of Imagination." This sheet instructed them to become part of the story and to vividly imagine the events in the story. The experimenter then briefly explained the purpose of the background music. Again, the experimenter did not mention words such as mood or feelings. The experimenter then began the audiotape and instructed subjects to read the story and complete the second packet of questionnaires. The experimenter then left the room.

The experimenter reentered the room when subjects signaled that they had completed the questionnaires and were ready to go on to the next phase. Upon reentering, the experimenter turned off the music and informed subjects that Phase 3 would take exactly $10 \mathrm{~min}$. Although the procedure for Phase 3 was parallel for all four response task groups, the experimental instructions varied depending on the activity level of the task.

Subjects in the passive groups received a sheet labeled "Sentence Understanding: Instructions." These instructions described the passive subjects' task as a sentence-reading exercise that required them to focus on the meaning and content of each sentence. The experimenter told subjects not to memorize the sentences, as this would distract their attention from the meaning of the sentences.

Subjects in the active groups received instructions describing the $Q$ sort method. To get subjects to be active, the experimenter demonstrated that the task must be done by taking individual cards, walking to the appropriate category heading, and then placing the card under that heading. To encourage subjects to remain standing during the task, their chairs were moved far away from the table.

In each condition, the experimenter emphasized that "all subjects must spend precisely the same amount of time on the experimental task" and that the assigned task must fill the entire time allotted for Phase 3 even if the task had to be repeated numerous times. The experimenter asked subjects to begin and then left the room.

After $10 \mathrm{~min}$, the experimenter opened the door slightly, leaned into the room, and told subjects to begin working on the final packet of questionnaires. Upon receiving the signal that subjects had completed the postresponse questionnaires, the experimenter reentered the room and revealed that the experimental portion of the study was complete. The remaining time was spent discussing the purpose of the experiment and the subjects' reactions to the experiment.

\section{Results}

\section{Overview of Findings}

Following the successful induction of depressed mood, the response tasks produced the predicted pattern of sadness remediation: Subjects in the distracting-active condition experienced the greatest decrease in sadness, followed by subjects in the distracting-passive condition, subjects in the ruminativeactive condition, and finally, subjects in the ruminative-passive condition. The findings indicate that degree of rumination had a greater influence on sadness remediation than did activity level and that degree of rumination and activity level did not interact. Rather, distraction and activity contributed to the remediation of depressed mood additively.

Subjects experienced increased feelings of hostility after the induction. The mean increase in sadness, however, was significantly greater than the mean increase in hostility. The induction procedure did not influence subjects' feelings of anxiety. The response tasks did not produce significant group differences in changes in hostility or anxiety.

We performed a number of analyses; therefore, we controlled the error rate experiment-wise. All $p$ values reported were adjusted using the Bonferroni method. In addition, all analyses of mood ratings were initially performed with sex of subject as a between-subjects factor. Because there were no significant main effects for or interactions with sex of subject, all analyses of mood ratings reported were conducted by collapsing across sex of subject. All $t$-test statistics reported herein are two-tailed unless otherwise stated.

\section{Manipulation Check: Assessing Postinduction Changes in Mood $^{2}$}

To assess the efficacy of the induction procedure, induction change scores were computed for each mood dimension by cal-

\footnotetext{
${ }^{2}$ Our use of difference scores in the present analyses is based on statistical and conceptual grounds. Recent discussions and examples have 13own that earlier criticisms of difference scores were based on restrictive and unrepresentative situations (i.e., data in which there is a high correlation between Time 1 and Time 2 scores), and that, under appropriate conditions, difference scores are actually unbiased estimates of true change (Rogosa, 1988). Rogosa and Willett (1983) presented detailed statistical and psychometric support for why change scores can serve as better estimates of change than can residuals. Our data satisfy the conditions under which change scores are reliable predictors of real change; for example, our correlations between pre- and postmeasures were low to moderate (i.e., less than .40). Because there
} 
Table 1

Mean Change in Sadness, Hostility, and Anxiety Following the Induction

\begin{tabular}{ccc}
\hline & \multicolumn{2}{c}{ Mean induction change } \\
score & $S D$ \\
\cline { 2 - 3 } Mood assessed & $M$ & $S$ \\
\hline Sadness & -3.64 & $1.24^{* *}$ \\
Hostility & -1.77 & $2.62^{*}$ \\
Anxiety & -0.61 & 2.43 \\
\hline
\end{tabular}

Note. Change scores significantly less than zero indicate an increase in the mood assessed.

$* p<.05$. ${ }^{* *} p<.001$.

culating the difference between subjects' pre-and postinduction mood ratings. The scores were analyzed initially using students' $t$ tests. Mean induction change scores significantly different from zero and negative indicate a significant increase in negative affect. Separate 2 (degree of rumination) $\times 2$ (activity level) analyses of variance (ANOVAS) were performed on induction change scores to assess whether there were group differences in changes in sadness, hostility, and anxiety prior to the response tasks. Data from five subjects (two women and three men) were not included in the analyses because these subjects failed to follow some aspect of the experimental instructions.

The induction procedure successfully induced depressed mood, $t(63)=23.49, p<.001$. There were no group differences in sadness induction change scores: degree of rumination, $F(1$, $60)=2.20, n s ;$ and activity level, $F(1,60)=0.12, n s$. Also, the interaction between the factors was not significant.

Hostility increased following the induction procedure, $t(63)=5.38, p<.001$. There were no group differences in hostility induction change scores: degree of rumination, $F(1,60)=$ $1.21, n s$; and activity level, $F(1,60)=1.01, n s$. The interaction between the factors was not significant. Levels of anxiety did not change significantly following the induction procedure, $t(63)=1.99, n s$. Table 1 presents the mean induction change scores for sadness, hostility, and anxiety.

We expected that the induction would produce increases in sadness that would be greater than increases produced in anxiety or hostility. Because there were no changes in anxiety, we compared only changes in sadness and hostility. Mean induction change scores for sadness and hostility were compared using a student's $t$ test. As expected, changes in sadness were sig-

were no differences between experimental groups in baseline or postinduction levels of sadness, anxiety, or hostility, it was not necessary to use covariance analysis to control for effects that baseline levels of affect might have had on subsequent levels. Furthermore, change scores provide a more direct and intuitive approach to addressing the main questions of this study: Is there a change in sadness following the induction? Are there changes in depressed mood after the response tasks? Given these questions and the fact that our data do not violate the conditions necessary for change scores to be reliable estimates of true change, change scores are both an intuitive and unbiased method of estimating the changes in mood. nificantly greater than changes in hostility, $t(63)=5.44, p<$ .0005 ; one-tailed.

\section{Effects of Degree of Rumination and Activity Level on Mood}

To assess the effects of the response tasks, response change scores were assessed using separate 2 (degree of rumination) $\times$ 2 (activity level) ANOVAs. These scores were derived, within each mood dimension, by taking the difference between each subject's postinduction and postresponse mood ratings. Response change scores greater than zero reflect remediation of negative affect and scores less than zero reflect intensification of negative affect.

The ANOVA performed on the sadness response change scores revealed significant main effects for degree of rumination, $F(1$, $60)=30.90, p<.001$, and activity level, $F(1,60)=10.24, p<$ .05 . The interaction between degree of rumination and activity level was not significant, $F(1,60)=0.15$, ns. These results indicate that the response tasks differentially influenced sadness and that the effects of degree of rumination and level of activity were additive. Figure 1 presents the mean response change scores for sadness and illustrates that the response tasks produced the predicted pattern of sadness remediation. The greatest amount of sadness remediation was found in the distracting-active condition $(M=4.03, S D=1.49)$, followed by the distracting-passive condition $(M=2.72, S D=1.24)$, the ruminative-active condition $(M=1.86, S D=1.49)$, and the ruminative-passive condition $(M=0.83, S D=1.61)$. Note that the mean decrease in sadness following the distracting-active task is roughly equal to the mean sadness increase following the induction $(M=-3.64, S D=1.24)$. The distracting-active task appears to have brought subjects' feelings of sadness down to preinduction levels. In contrast, the ruminative-passive task produced little change in sadness.

The ANOVA demonstrated that the response tasks did not produce differential changes in hostility: degree of rumination,

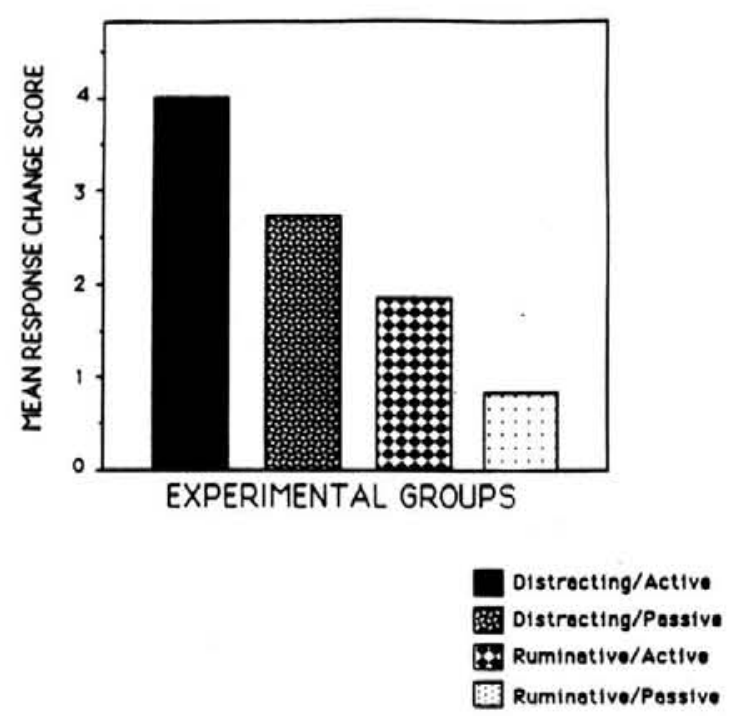

Figure I. Mean response change scores for sadness. 
$F(1,60)=0.84, n s$; activity level, $F(1,60)=0.07, n s ;$ and Degree of Rumination $\times$ Activity Level, $F(1,60)=0.20$, ns. The response tasks also did not produce group differences in changes in anxiety: degree of rumination, $F(1,60)=3.10, n s$; activity level, $F(1,60)=1.01, n s$; and Degree of Rumination $\times$ Activity Level, $F(1,60)=1.36, n s$.

In sum, the assigned response tasks influenced sadness as predicted. The distracting-active task was the most effective in remediating sadness and the ruminative-passive task was the least effective. In addition, the effects of the response tasks were limited to sadness.

\section{Discussion}

Consider two individuals, Lee and Chris, who find themselves feeling sad, lethargic, unmotivated, and generally depressed one morning. Lee decides to cancel all appointments for the morning and to retreat into the office. While in the office, Lee thinks "I wonder why I feel the way I do," "I'm feeling down," and "I've got to think about this." In contrast, Chris decides to respond to the depressed mood by going to the library and concentrating on gathering the background research for a new project.

The results of the study reported here strongly suggest that Lee, who engaged in a passive, ruminative response to the depressed mood, will remain depressed for an extended period, whereas Chris, who engaged in an active, distracting response, will experience relief from the depressed mood. The results also suggest that the extent to which Lee or Chris engage in ruminative thoughts about their moods will have a greater influence on the alleviation of their moods than their level of physical activity. That is, it will be more important for Lee and Chris to find some way to take their attention away from their moods than to engage in physical activity, although either distraction or activity will aid in the alleviation of depressed mood. In the study reported here, activity may have had a greater effect on sadness remediation if the level of activity had been higher or had it clearly provided positive reinforcement. But we suspect that degree of rumination of responses will typically be more strongly related to duration of depressed mood than activity level, because even while being active, one can still ruminate.

On the basis of the response styles theory (Nolen-Hoeksema, 1987), we might have expected that subjects who engaged in passive rumination in response to depressed mood would have shown exacerbation of their depressed mood rather than only maintenance of the mood. However, the ruminations that subjects were asked to engage in were not particularly negative. Rather, they were ponderous and self-reflective thoughts, such as "I wonder why things turn out the way they do." We expect that if we had asked subjects to engage in more negative ruminations, we would have seen an actual exacerbation of the subjects' depressive mood.

Some people, when depressed, engage in ponderous rumination in an attempt to understand the causes and implications of their depressed mood. Despite the good intentions behind such responses, they can backfire and maintain the depressed mood. Let us say that Lee (from the example above) begins to ponder the possible causes and implications of being depressed. The cause of Lee's depressed mood might have been some clearly identifiable negative event (e.g., his boss had yelled at him). If so, recognizing the cause of the depression may help to stop his ruminations, although, if he makes pessimistic attributions for his boss having yelled at him, he might still remain depressed (cf. Abramson, Seligman, \& Teasdale, 1978). In addition, he might continue to ruminate on the implications of his boss's disfavor even after he recognizes the cause of his depression, thus keeping himself depressed. Often, however, the causes of a depressed mood are quite unclear (cf. Schwarz \& Clore, 1988). If this were the case for Lee, and he thinks about the possible causes and implications of his depressed mood, he may consider not only recent bad events but his relationships with others, career progress, and personality traits. While considering information about his functioning in these domains, Lee will likely focus on negative information because access to negative information is increased when individuals are in depressed moods (Blaney, 1986). Also, simply the fact that Lee is depressed may lead him to expect that there is something wrong in one or more of these areas. Sometimes this may be true. But the response styles theory would predict that if Lee ponders the causes and implications of his mood while depressed, he will be more likely to reach depressing conclusions than if he considers the sources of his depressed mood after the mood has lifted.

Compare Chris's response to his depressed mood to Lee's response. Chris responded to his depression by going to the library and concentrating on research. On the basis of the present findings, we would expect that Chris's distracting response would lead to relief from his mood. Now that his mood has lifted, Chris can think about the causes and implications of his earlier depression without his thinking being influenced by the effects of depressed mood. After his initial distraction, Chris's search leads him to realize that he became depressed because his boss had yelled at him. Chris will be less likely to make negative attributions about his boss's behavior because he will no longer be in a depressed mood.

What if the causes of Chris's depressed mood were unclear? Chances are, if Chris considers various aspects of his life in searching for possible causes of his depression, he will not focus primarily on negative information because this information will not be more accessible. In fact, because Chris has successfully overcome his depressed mood, he may have enhanced his sense of control, thereby providing self-reinforcement and making him feel more positive. Additionally, going to the library may have provided Chris with direct reinforcement. Being productive and working on new ideas is more likely to be rewarding than sitting in the office and doing nothing. Because of the effects of active distraction on mood, control, and reinforcement, Chris will not only experience relief from his depressed mood, but he will be more likely than Lee to recall good things when he thinks about various aspects of his life.

The results of this study indicate that having moderately saddened subjects engage in active distraction leads to relief of their mood. Yet, are seriously depressed persons capable of using distraction to relieve their depressed moods? Recent studies suggest they are. Wenzlaff, Wegner, and Roper (1988) asked depressed and nondepressed subjects to imagine themselves as the protagonist in a very distressing story about someone who accidently kills a child in a car accident. Then they asked the subjects to write down any thoughts that came to mind for the next $9 \mathrm{~min}$, but to try not to think of the story. Left on their own, 
the depressed subjects tended to use other negative thoughts to distract themselves from the incidents in the story they had read, whereas the nondepressed subjects tended to use positive thoughts to distract themselves. But when the depressed subjects were actually provided with positive distractors and told to use them to suppress the negative thoughts, they could and did. Wenzlaff and colleagues suggested that depressed persons have such greater access to negative thoughts than positive thoughts that it is difficult for them to use positive thoughts to distract themselves. But when given help in using positive distractors, depressed persons can use them.

Fennell and Teasdale (1984) found that distraction helps to alleviate the mood of severely depressed persons. In a withinsubjects design, clinically depressed patients were put through a distraction condition and a control condition, in randomized order. In the distraction condition, subjects were asked to view slides of outdoor scenes and describe them out loud as vividly as possible. In the control condition, subjects simply sat quietly, looking at the wall. Each condition lasted $5 \mathrm{~min}$, and measures of depressed affect were taken before and after each condition. As predicted, the distraction condition led to significant decreases in depressed mood, whereas the control condition led to substantial increases in depressed mood. In addition, subjects in the distraction condition reported a lower number of negative ruminations than did subjects in the control condition. Thus, distraction helped to reduce ruminations in these clinically depressed patients, and the reduction of ruminations was associated with reductions in depression.

Should individuals never attend to their depressed moods? Obviously, if an individual frequently becomes depressed, he or she should consider possible causes for these episodes and ways to prevent them from happening in the future. The response styles theory suggests, however, that this thinking should be done after the individual has found some way to relieve his or her depressed mood, so that the mood does not affect his or her deliberations (see Nolen-Hoeksema, in press). Are all forms of distraction adaptive? Obviously not. Some distracting responses are inherently maladaptive, such as excessive drinking or drug use and aggressive behavior. Individuals who engage in these forms of distraction may not be depressed much of the time, but they may be vulnerable to other forms of pathology (see Ingram, Cruet, Johnson, \& Wisnicki, 1988; Nolen-Hoeksema, in press). The results of this study clearly indicate, however, that ruminative focus on one's emotion is also not to be recommended as an effective way of responding to depression.

The response styles theory was originally proposed to account for the greater tendency for women than men to show depression. Nolen-Hoeksema (1987) argued that women are more likely than men to show depression because they tend to have a more ruminative style of responding to their depressed moods. Questionnaire studies have supported this sex difference in response styles (cf. Nolen-Hoeksema, 1987). Results from a recent laboratory study, in which the responses of men and women to induced distress were observed, also provide evidence for a sex difference in styles. Ingram et al. (1988) found that women responded with greater levels of self-focus, and in turn more negative affect, to a negative event occurring during an experiment than did men.

In this study, we did not assess subjects' actual styles of re- sponding to depressed mood; rather we manipulated responses to depressed mood in a controlled fashion. As such, we do not know whether or not there were sex differences in the response styles the subjects brought to the study. We do know, however, that there were no sex differences in the effects of the responses we assigned to the subjects on the remediation of sad mood. That is, ruminative and passive responses were equally deleterious, and distracting and active responses were equally beneficial, to both the men and women. This suggests that both sexes can be taught to use adaptive distracting, active responses rather than ruminative, passive ones when they are depressed, with positive effects on both men's and women's levels of depression.

The responses assigned to subjects in this study affected their levels of sad mood but not their levels of anxiety and hostility. This may have been because subjects were experiencing primarily a depressed mood: The induction did not produce significant increases in anxiety, and the induction produced increases in hostility that were much smaller than the increases in sadness. Would passive rumination by individuals who were very anxious or hostile increase and maintain the levels of these moods? Studies on the effects of self-focused attention suggest that indeed this would be the case. It is known that self-focus tends to elevate existing internal states, including feelings of anxiety, fear, sadness, repulsion, and attraction (cf. Carver \& Scheier, 1981). In addition, there is considerable evidence that task-irrelevant, self-focused cognitions are associated with heightened levels of anxiety during the performance of achievement-related tasks (cf. Sarason, 1975). Although there have been few studies on the effects of self-focus and hostility, Scheier (1976) demonstrated that among subjects who were provoked, more intense anger was reported by subjects who were self-attentive. Consistent with these findings, associative network theory would predict that any type of mood state would make mood-congruent cognitions more accessible. Consequently, ruminative self-focus should help to maintain an existing mood by making mood-congruent thoughts and memories relatively more available (Teasdale, 1985). Therefore, we argue that the effects of rumination should not be limited to depressed mood; rather, rumination would be expected to have parallel effects on other negative moods, given that the moods are sufficiently aroused.

The study of the effects of individuals' responses on the duration of depression and other negative moods holds considerable promise for guiding intervention programs. Depressed persons often feel unable to control their symptoms of depression, and the resulting sense of helplessness often seems to exacerbate their depression (Teasdale, 1985). Teaching individuals more adaptive means of responding to their negative moods may help them recover from a current negative mood. This may give them an added sense of control and facilitate other types of interventions as well. For example, Teasdale (1985) found that depressed patients who received drug treatment and cognitive therapy focused on skills for controlling one's depression, such as "distraction activity to reduce frequency of ruminations" (p. 160 ), showed more rapid decreases in depression than patients who received only drug treatment. Thus, an understanding of the effects of response styles on depressed mood will be useful both to theorists attempting to understand individual differ- 
ences in the duration of depressed moods and to clinicians attempting to help depressed people control their depression.

\section{References}

Abramson, L. Y., Seligman, M. E. P., \& Teasdale, J. (1978). Learned helplessness in humans: Critique and reformulation. Journal of $A b$ normal Psychology, 87, 49-74.

Alloy, L. B., Abramson, L. Y., \& Viscusi, D. (1981). Induced mood and the illusion of control. Journal of Personality and Social Psychology, 41, 1129-1140.

Bahrke, M. S., \& Morgan, W. P. (1978). Anxiety reduction following exercise and meditation. Cognitive Therapy and Research, 2, 323333.

Batson, C. C., Coke, J. S., Chard, F., Smith, D., \& Taliaferro, A. (1979). Generality of the "glow of goodwill": Effects of mood on helping and information acquisition. Social Psychology Quarterly, 46, 293-301.

Beckham, E. E., \& Leber, W. R. (Eds.). (1985). Handbook of depression: Treatment, assessment, and research. Homewood, IL: Dorsey Press.

Blaney, P. H. (1986). Affect and memory: A review. Psychological Bulletin, 99, 229-246.

Block, J. (1961). The Q-sort method in personality assessment and psychiatric research. Springfield, IL: Thomas.

Bower, G. H. (1981). Mood and memory. American Psychologist, 36, 129-148.

Brockner, J., \& Hulton, A. J. B. (1978). How to reverse the vicious cycle of low self-esteem: The importance of attentional focus. Joumal of Experimental Social Psychology, 14, 564-578.

Byrd, O. E. (1964). Viewpoints of bowlers in respect to the relief of tension. Physical Education, 21, 119.

Carver, C. S., Blaney, P. H., \& Scheier, M. F. (1979). Reassertion and giving up: The interactive role of self-directed attention and outcome expectancy. Journal of Personality and Social Psychology, 37, 1859. 1870.

Carver, C. S., \& Scheier, M. F. (1981). Attention and self-regulation: A control-theory approach to human behavior. New York: Springer.

Clark, D. M. (1983). On the induction of depressed mood in the laboratory: Evaluation and comparison of the Velten and musical procedures. Advances in Behavioral Research and Therapy, 5, 27-49.

Clark, D. M., \& Teasdale, J. D. (1982). Diurnal variation in clinical depression and accessibility of memories of positive and negative experiences. Journal of Abnormal Psychology, 91, 87-95.

Coyne, J. C., Aldwin, C. M., \& Lazarus, R. S. (1981). Depression and coping in stressful episodes. Journal of Abnormal Psychology, 90 , 439-447.

Coyne, J. C., Metalsky, G. I., \& Lavelle, T. L. (1980). Learned helplessness as experimenter-induced failure and its alleviation with attentional redeployment. Journal of Abnormal Psychology, 89, 350-357.

Doyne, E. J., Chambless, D. L., \& Beutler, L. E. (1983). Aerobic exercises as a treatment for depression in women. Behavior Therapy, 14, $434-440$.

Felton, B. J., \& Revenson, T. A. (1984). Coping with chronic illness: A study of illness controllability and the influence of coping strategies on psychological adjustment. Journal of Consulting and Clinical Psychology: 32, 343-353.

Fenigstein, A. (1979). Self-consciousness, self-attention, and social interaction. Journal of Personality and Social Psychology, 37, 75-78.

Fenigstein, A., \& Levine, M. P. (1984). Self-attention, concept activation, and the causal self. Journal of Experimental Social Psychology, $20,231-245$.

Fennell, M. J., \& Teasdale, J. D. (1984). The effects of distraction on thinking and affect in depressed patients. British Journal of Clinical Psychology 23, 65-66.

Forgas, J. P., \& Bower, G. H. (1987). Mood effects on person-perception judgments. Journal of Personality and Social Psychology, 53, 53-60.
Forgas, J. P., Bower, G. H., \& Krantz, S. E. (1984). The influence of mood on perception of social interactions. Journal of Experimental Social Psychology, 20, 497-513.

Fuchs, C. Z., \& Rehm, L. P. (1977). A self-control behavior therapy for depression. Journal of Consulting and Clinical Psychology, 45, 206215.

Gibbons, F. X., Smith, T. W., Ingram, R. E., Pearce, K., Brehm, S. S., \& Schroeder, D. (1985). Self-awareness and self-confrontation: Effects of self-focused attention on members of a clinical population. Journal of Personality and Social Psychology, 48, 662-675.

Greist, J. H., Klein, M. H., Eischens, R. R., Faris, J., Gurman, A. S., \& Morgan, W. P. (1979). Running as treatment for depression. Comprehensive Psychiatry, 20, 41-53.

Heckhausen, H. (1980). Task-irrelevant cognitions during an exam: Incidence and effects. In H. W. Krohne \& L. Laux (Eds.), Achievement, stress, and anxiety (pp. 247-274). Washington, DC: Hemisphere.

Heiby, E. M. (1983a). Depression as a function of the interaction of self and environmentally controlled reinforcement. Behavior Therapy. 14, 430-433.

Heiby, E. M. (1983b). Toward a prediction of mood change. Behavior Therapy, 14, 110-115.

Ingram, R. E., Cruet, D., Johnson, B. R., \& Wisnicki, K. S. (1988). Selffocused attention, gender, gender role, and vulnerability to negative affect. Journal of Personality and Social Psychology, 55, 967-978.

Keltner, D., \& Ellsworth, P. (1987). Emotion specific influences on judgments of responsibility. Unpublished manuscript, Stanford University, Department of Psychology.

Kuhl, J. (1981). Motivational and functional helplessness: The moderating effect of state versus action orientation. Journal of Personality and Social Psychology, 40, 155-170.

Lewinsohn, P. M. (1986). A behavioral approach to depression. In J. C. Coyne (Ed.), Essential papers on depression (pp. 150-172). Now York: New York University Press.

Lewinsohn, P. M., Hoberman, H., Teri, L., \& Hautzinger, M. (1985). An integrative theory of depression. In S. Reiss \& R. Bootzin (Eds.), Theoretical issues in behavior therapy (pp. 331-359). New York: Academic Press.

Lewinsohn, P. M., \& Libet, J. (1972). Pleasant events, activity schedules, and depression. Journal of Abnormal Psychology, 79, 291-295.

McCann, 1. L., \& Holmes, D. S. (1984). Influence of aerobic exercise on depression. Journal of Personality and Social Psychology, 46, 11421147.

Morgan, W. P. (1985). Affective beneficence of vigorous physical activity. Medicine and Science in Sports and Exercise, 17, 94-106.

Morrow, J. (1986). The effects of mood on judgments of event likelihood. Unpublished manuscript, Stanford University, Department of Psychology.

Natale, M., \& Hantas, M. (1982). Effect of temporary mood states on selective memory about the self. Journal of Personality and Social Psychology, 42, 927-934.

Needles, D. J. (1987). Coping styles and their effects on depressed mood. Unpublished manuscript, Stanford University, Department of Psychology.

Nolen-Hoeksema, S. (1987). Sex differences in unipolar depression: Evidence and theory. Psychological Bulletin, 101, 259-282.

Nolen-Hoeksema, S. (in press). Sex differences in depression. Stanford, CA: Stanford University Press.

Parker, G. B., \& Brown, L. B. (1982). Coping behaviors that mediate between life events and depression. Archives of General Psychiatry, 39, 1386-1391.

Pyszczynski, T., \& Greenberg, J. (1987). Self-regulatory perseveration and the depressive self-focusing style: A self-awareness theory of reactive depression. Psychological Bulletin, 201, 122-138.

Pyszczynski, T., Holt, K., \& Greenberg, J. (1987). Depression, self-fo- 
cused attention, and expectancies for positive and negative future life events for self and others. Journal of Personality and Social Psychology, 52, 994-1001.

Rehm, L. P. (1982). Self-management in depression. In P. Karaly \& F. H. Kanfer (Eds.), Self-management and behavior change: From theory to practice (pp. 522-567). New York: Pergamon Press.

Rehm, L. P. (1986). A self-control model of depression. In J. C. Coyne (Ed.), Essential papers on depression (pp. 220-239). New York: New York University Press.

Rogosa, D. R. (1988). Myths about longitudinal research. In K. W. Schaie, R. T. Campbell, W. Meredith, \& S. C. Rawlings (Eds.), Methodological issues in aging research. New York: Springer.

Rogosa, D. R., \& Willett, J. B. (1983). Demonstrating the reliability of the difference score in measurement of change. Journal of Educational Measurement, 20, 335-343.

Sarason, I. G, (1975). Anxiety and self-preoccupation. In I. G. Sarason \& C. D. Spielberger (Eds.), Stress and anxiety (pp. 27-44). Washington, DC: Hemisphere.

Scheier, M. F. (1976). Self-awareness, self-consciousness, and angry aggression. Journal of Personality, 44, 627-644.

Scheier, M. F., \& Carver, C. S. (1977). Self-focused attention and the experience of emotion: Attraction, repulsion, elation, and depression. Journal of Personality and Social Psychology, 35, 625-636.

Schwarz, N., \& Clore, G. L. (1988). How do I feel about it? The informative function of affective states. In K. Fiedler \& J. Forgas (Eds.), Affect, cognition, and social behavior (pp. $\mathrm{xxx}-\mathrm{xxx}$ ). Toronto: Hogrefe International.
Seligman, M. E. P. (1975). Helplessness: On depression, development and death. San Francisco: Freeman.

Strack, S., Blaney, P. H., Ganellen, R. J., \& Coyne, J. C. (1985). Pessimistic self-preoccupation, performance deficits, and depression. Journal of Personality and Social Psychology. 49, 1076-1085.

Sutherland, G., Newman, B., \& Rachman, S. (1982). Experimental investigations of the relations between mood and intrusive unwanted cognitions. British Journal of Medical Psychology, 55, 127-138.

Teasdale, J. D. (1985). Psychological treatments for depression: How do they work? Behavior Research and Therapy, 23, 157-165.

Teasdale, J. D., \& Fogarty, S. J. (1979). Differential effects of induced mood on retrieval of pleasant and unpleasant events from episodic memory. Journal of Abnormal Psychology, 88, 248-257.

Wenzlaff, R. M., Wegner, D. M., \& Roper, D. W. (1988). Depression and mental control: The resurgence of unwanted negative thoughts. Joumal of Personality and Social Psychology. 55, 882-892.

Zullow, H. M. (1984). The interaction of rumination and explanatory style in depression. Unpublished master's thesis, University of Pennsylvania.

Zullow, H. M., Oettingen, G., Peterson, C., \& Seligman, M. E. P. (1988). Pessimistic explanatory style in the historical record. American Psychologist, 43, 673-682.

Received October 30, 1988

Revision received June 28, 1989

Accepted July 28, 1989 